\title{
Exploring characteristics associated with first benzodiazepine prescription in patients with affective disorders and related diagnoses
}

\section{Running Head: first benzodiazepine prescription in affective disorders}

V. De Carlo ${ }^{1}$, B. Grancini ${ }^{1}$, M. Vismara ${ }^{1}$, B. Benatti ${ }^{1}$, C. Arici ${ }^{1}$, L. Cremaschi ${ }^{1}$, G. Cirnigliaro ${ }^{1}$, L. Degoni $^{1}$, L. Oldani ${ }^{4}$, M.C. Palazzo ${ }^{1}$, I.D. Glick ${ }^{2}$, C.A. Viganò ${ }^{1}$, B. Dell’Osso ${ }^{1,2,3 *}$

${ }^{1}$ Department of Biomedical and Clinical Sciences "Luigi Sacco", University of Milan, Psychiatry Unit, ASST Fatebenefratelli-Sacco, Milan, Italy.

${ }^{2}$ Department of Psychiatry and Behavioral Sciences, Stanford Medical School, Stanford University, Stanford, CA, USA.

${ }^{3} \mathrm{CRC}$ "Aldo Ravelli" for Neurotechnology \& Experimental Brain Therapeutics, University of Milan, Milan, Italy.

${ }^{4}$ Department of Mental Health, Fondazione IRCCS Cà Granda Policlinico, Milan, Italy.

*Corresponding Author:

Prof. Bernardo Dell'Osso, Associate Professor of Psychiatry, University of Milan, Department of Biomedical and Clinical Sciences "Luigi Sacco", ASST Fatebenefratelli-Sacco, via G. B. Grassi 74, 20157 Milano, Italy.

Tel. +390239042904Fax 0239042320 


\section{ACKNOWLEDGEMETS}

We thank the patients who took part in this project and the colleagues who, over the years, contributed to the data collection: Drs Filippo Castellano, Nazario D’Urso, Diego Primavera, Neva Suardi, Alma Cattaneo and Matteo Maggi.

\section{CONFLICT OF INTEREST}

V. De Carlo, B. Grancini, M. Vismara, B. Benatti, C. Arici, L. Cremaschi, G. Cirnigliaro, L. Degoni, L. Oldani, M.C. Palazzo, C.A. Viganò report no financial relationships with commercial interests.

Prof. Dell'Osso has received Grant/Research Support from Livanova, Inc., Angelini and Lundbeck; and Lecture Honoraria from Angelini, FB Health and Lundbeck.

In the last year, Dr. Glick has been on Advisory Boards for Neurocrine and Forum, Speakers Bureaus for Neurocrine and Synovian and has equity in Johnson \& Johnson. Dr Olfson has no disclosures.

\section{PATIENT CONSENT}

The present study was conducted according to the principles expressed in the Declaration of Helsinki and partially supported by a research grant (Scientific Productivity Fund), annually provided by the Fondazione IRCCS Ca' Granda of Milan. 


\begin{abstract}
Objective. Affective disorders are prevalent and burdensome conditions. Among medications prescribed at the onset, benzodiazepines (BZDs) are frequently administered, despite not being guideline-recommended. The present study sought to identify clinical variables associated with first BZD prescription, in order to elucidate reasons for their initial administration, in 460 patients with mood or anxiety disorders.
\end{abstract}

Methods. Statistical analyses (one-wayANOVA and $\chi 2$ test) were conducted to compare patients who received BZD as first treatment (BZDw/) and those who did not (BZDw/o).

Results. In the whole sample more than 1/3 (35.7\%) had received BZDs as first prescription. In relation to mood disorders, BZDw/ subjects more frequently had 1) not a psychiatrist as first therapist, 2) anxious symptoms at onset, 3) Adjustment Disorder (AD) as first diagnosis, 4) were less frequently treated as inpatients. In relation to specific diagnoses, 1) personal decision of treatment for Major Depressive Disorder, 2) outpatient status for Bipolar Disorder and 3) longer duration of untreated illness for $\mathrm{AD}$ were more frequently associated with first BZD prescription. For anxiety disorders, BZDw/ was related to the presence of stressful life events and to diagnoses of Panic Disorder or specific phobias.

Conclusion. Patients with affective disorders were found to frequently receive BZDs as first prescription with significant differences between and within mood and anxiety disorders.

Key words: affective disorders, benzodiazepines, first prescription. 


\section{INTRODUCTION}

Affective disorders are prevalent, comorbid and burdensome conditions with a frequent chronic course of illness (Charara et al., 2017). Especially for mild forms of illness, patients with affective disorders are not treated in psychiatric services, being frequently managed by general practitioners (GPs) (Baldwin, Allgulander, Bandelow, Ferre, \& Pallanti, 2012; Dell'Osso et al., 2015; Dell'Osso \& Lader, 2013). The tendency to be initially treated by GPs rather than psychiatrists might be related to the stigma towards mental illnesses and psychotropic drugs (Del Vecchio et al., 2015; Falloon, 2000; Skeate, Jackson, Birchwood, \& Jones, 2002; Tait, Lester, Birchwood, Freemantle, \& Wilson, 2005). Particularly at the onset of psychiatric symptoms, when a proper diagnosis is missing or when the symptomatology is underestimated (Dell'Osso et al., 2016), patients may be initially treated with symptomatic drugs, particularly with benzodiazepines (BZDs). In fact, these compounds are among the most widely prescribed classes of psychotropics, regardless of the diagnosis (Dell'Osso \& Lader, 2013).(Busto \& Sellers, 1991)(Bushnell, Stürmer, Gaynes, Pate, \& Miller, 2017; Paquin, Zimmerman, \& Rudolph, 2014) For this reason, many studies investigating BZDs prescription patterns at the onset of different psychiatric disorders (Straand \& Rokstad, 1997), emphasized, in particular, how these compounds are frequently misused and highlighted the importance to decrease their inappropriate use. Nonetheless, BZDs are often administered inappropriately to elderly population and patients often hesitate to discontinue BZDs, due to symptoms of withdrawal or relapse (Bushnell, Stürmer, Gaynes, Pate, \& Miller, 2017; Paquin, Zimmerman, \& Rudolph, 2014). BZDs have moreover well-established efficacy and safety, but also abuse potential abuse, and prolonged self-administration of low doses may be maintained to alleviate withdrawal symptoms (Busto \& Sellers, 1991).

BZDs are often prescribed in different psychiatric disorders (Dell'Osso \& Lader, 2013; Nardi et al., 2010)., including mood and anxiety disorders. Nonetheless, among available medications, BZDs are not recommended for mood disorders by International treatment guidelines, considering the lack of antidepressant effect and risk of long-term side effects (B Dell'osso \& Lader, 2013). Similar limitations exist for anxiety disorders. In fact, high-potency BZDs are widely used in the treatment of panic disorder because of their rapid onset of action and favourable acute tolerability, ignoring relevant discontinuation symptoms that can occur after long-term use (Antonio E Nardi et al., 2010).

In light of the above, when recommended, BZDs should be administered in affective disorders exclusively as an adjunctive acute treatment, in order to avoid the long-term risk of abuse/addiction 
(Janhsen, Roser, \& Hoffmann, 2015) and even short-term users should be aware of the potential risk of dependence(Anthierens et al., 2007). Straand and Rokstad previously observed in a large population study (3452 patients) that $81.9 \%$ of BZD prescriptions were repeated ones, underlying the potential risk of dependence and the difficulty of BZD discontinuation (Straand \& Rokstad, 1997). theMoreover, a recent Norwegian study reported that a diagnosis of psychiatric disorder and the use of BZDs as first treatment choice could be risk factors for subsequent BZDs misuse (Fride Tvete, Bjørner, \& Skomedal, 2015). Focusing on BZDs as first pharmacological prescription, our group previously reported that their initial administration could delay the implementation of a guideline-recommended adequate treatment (i.e., increasing the duration of untreated illness or DUI) in a large sample of patients affected by different psychiatric disorders (Grancini et al., 2018). Therefore, in the present study, we quantified first BZD prescription in total patients and related groups and then assessed clinical variables associated with BZDs first prescription in patients with

affective disorders, with a specific focus on first therapist (psychiatrist/non psychiatrist). Secondarily, we tried to characterize patients with BZDs first prescription across specific affective disorders. We hypothesized to find different rates of BZD first prescription between patients with mood spectrum vs anxiety spectrum disorders along with distinct clinical variables associated to their use.

\section{METHODS}

For the present study, 460 in and out-patients, recruited in three major psychiatric services in the North and South of Italy, were analysed. Details related to catchment areas have been specified elsewhere (Grancini et al., 2018). In order to obtain the psychiatric diagnosis and collect sociodemographic and clinical variables, patients underwent a clinical interview after providing their written informed consent to participate to the study. Collected variables were additionally integrated through patients' clinical records review. The Diagnostic and Statistical Manual of Mental Disorders, 4th ed., Text Revision (DSM IV-TR) (American Psychiatric Association, 2000) was used to assess patients' diagnosis. Total sample was then divided in two diagnostic groups: 304 patients with mood spectrum disorders (193 subjects affected by Major Depressive Disorder (MDD), 83 by Bipolar Disorder (BD) and 28 by Adjustment Disorder (AD)) and 156 patients with anxiety spectrum disorders (71 subjects with of Generalized Anxiety Disorder (GAD), 49 Panic Disorder (PD) and 36 Obsessive Compulsive Disorder (OCD)). e.g.Diagnoses were made through the Structured Clinical Interview for DSM-IV Axis I disorders (First MB, Michael B, 2002), administered by psychiatrists with specific training. 


\section{Assessment}

Main demographic and clinical variables, collected during clinical interviews, were: gender, age, age at onset, age at first diagnosis, age at first pharmacological treatment, first pharmacological treatment, family history for psychiatric disorders, occurrence of onset-related stressful events, use of BZDs as first treatment, first therapist (psychiatrist, psychologist, GP or other clinician), helpseeking decision (autonomous or driven by others) and first therapy setting (outpatient or inpatient). In particular, all patients were administered the psychopathological onset and latency to treatment questionnaire (POLT-Q), a recently developed tool aimed to specifically assess factors characterizing access and latency to first pharmacological treatment in patients suffering from psychiatric disorders. POLT-Q is a brief, clinician administered questionnaire that was found to be easy to administer by clinicians and well-accepted by patients (Dell'Osso B, Palazzo C, 2011). As conventionally accepted (Dell'osso \& Altamura, 2010; Dell'Osso, Camuri, Benatti, Buoli, \& Altamura, 2013), DUI was defined as the time interval - in months - elapsing between the onset of the disorder and the administration of the first pharmacological treatment, in compliant subjects, at appropriate dosage and for an adequate period of time, in agreement with recently updated International treatment guidelines of affective disorders (Bauer et al., 2013; Grunze et al., 2013). In case of comorbidity, the assessed disorder was considered the one causing the most significant discomfort to the patient, the greatest impact on his/her quality of life and representing the main motivation for help-seeking.

\section{Statistical analysis}

Descriptive and comparative analyses were performed within the two diagnostic groups and across specific diagnoses. Study sample was divided into two subgroups according to the use of BZDs as first treatment. One-way ANOVA for continuous variables and $\chi 2$ test for dichotomous ones were performed for comparison between patients who used BZDs as first treatment (BZD w/) and those who did not (BZD w/o), with Bonferroni's correction. The level of significance for all statistical analyses was set at 0.05 .

\section{RESULTS}

Demographic and clinical variables of the whole sample and related subgroups $(n=460)$ are summarized in Table 1.

A similar gender distribution emerged (male 51.3\% and females $48.7 \%$ ), with a mean age of $48.57 \pm 14.35$ years. The DUI of the total sample resulted to be $62.28 \pm 103.16$ months. 
In the whole sample more than $1 / 3$ of the subjects $(35.7 \%)$ had received BZD as first prescription, with a slightly higher proportion of BZD w/ in the group of mood disorders compared to anxiety disorders $(36.8 \%$ vs $33.3 \% \mathrm{p}=0.46)$.

In the subgroup of patients with mood spectrum disorders $(n=304), 37 \%(n=112)$ of patients reported a first prescription with BZD, while in the sample with anxiety spectrum disorders $(n=156)$ $33 \%(n=52)$ had been initially treated with a BZD. Statistically significant differences between BZD w/ and BZD w/o for patients with mood and anxiety spectrum disorders and related diagnoses are reported in Table 2.

In the context of mood disorders, BZD w/ patients were more frequently outpatients than inpatients (respectively $88.9 \%$ vs $77.5 \%, \mathrm{p}<0.05$ and $11.7 \%$ vs $22.5 \%, \mathrm{p}<0.05$ ) and more often had anxious symptoms at onset $(22.3 \%$ vs $10.5 \%, \mathrm{p}<0.01)$, while depressive, psychotic or other symptoms at onset did not show different rates between the two considered groups. Moreover, BZD w/ subjects were more frequently affected by $\mathrm{AD}(14.3 \%$ vs $6.3 \%, \mathrm{p}<0.001)$ and less frequently by $\mathrm{BD}(16.1 \%$ vs $33.9 \%$, $\mathrm{p}<0.001$ ) compared to BZD w/o ones, while MDD prevalence did not result significantly different between the two groups, after Bonferroni's correction. Psychologists or other doctors (in particular GPs) were more frequently the first professionals treating BZD w/ vs w/o patients (respectively $22.3 \%$ vs $7.9 \%$, p <0.0001; $51.3 \%$ vs $38.2 \%$, p<0.0001) compared with psychiatrists $(25.9 \%$ vs $53.9 \%, \mathrm{p}<0.0001)$. Other socio-demographic and clinical features did not show any other statistically significant difference between the two subgroups.

Taking into consideration specific diagnoses of mood spectrum disorders, among patients with MDD, BZD w/ patients more frequently sought professional help following a personal decision compared to BZD w/o ones $(53.5 \%$ vs $38.5 \%$, p<0.05). Moreover, psychologists more frequently were the first therapists $(21.8 \%$ vs $11.3 \%, \mathrm{p}<0.01)$ compared to psychiatrist $(23.1 \%$ vs $43.5 \%$, $\mathrm{p}<0.01)$. Among bipolar subjects, BZD w/ ones were more frequently outpatients (88.9\% vs 59.4\%, $\mathrm{p}<0.05)$ than inpatients $(11.1 \%$ vs $40.6 \%, \mathrm{p}<0.05)$. Finally, the DUI was found to be longer in BZD w/ patients affected by $\mathrm{AD}(38.3 \pm 63.2$ vs $3.0 \pm 5.4$ months, $\mathrm{p}<0.05)$.

Considering the anxiety spectrum disorders, gender, presence of phobias and stressful life events significantly differed among BZDs w/ vs BZD w/o patients. More in detail, BZD w/ subjects were more frequently of female gender $(60.0 \%$ vs $35.0 \%, \mathrm{p}<0.01)$ and more often presented phobias $(47.0 \%$ vs $23.0 \%, \mathrm{p}<0.01)$ and stressful events $(79.0 \%$ vs $58 \%, \mathrm{p}<0.05)$ than BZD w/o ones. As in the mood spectrum disorders, the first therapist in BZD w/ patients was less often a psychiatrist $(17.0 \%$ vs $48.0 \%, \mathrm{p}<0.01)$ and more frequently other therapist $(62.0 \%$ vs $40.0 \%, \mathrm{p}<0.01)$. Furthermore, GAD diagnosis was more common in BZD w/ patients $(58.0 \%$ vs $39.0 \%$, p<0.05), 
while OCD diagnosis was less frequent $(10.0 \%$ vs $30.0 \%, \mathrm{p}<0.05)$. Analyses within specific diagnoses (OCD, GAD and PD) did not show any statistically significant difference.

\section{DISCUSSION}

In the present study, we aimed to quantify first BZD prescription and to assess related clinical variables in a large sample of patients with mood and anxiety disorders. In addition, we tried to characterize patterns of BZDs' first prescription across specific diagnoses, due to the paucity of data in the field.

Focusing on BZD w/ patients, representing more than one thirs of the overall sample and, respectively, the $37 \%$ of the mood disorders group and the $33 \%$ of the anxiety one, descriptive analyses showed a mean time elapsing from the first BZD use and the first prescription of an adequate (non symptomatic) pharmacological treatment of $48.01 \pm 79.15$ months: approximately 4 years. This finding indicates that patients, who initially had received a BZD prescription, ended up receiving a guideline-recommended different treatment years later. This gap likely reflects the mean latency to first diagnosis, which was found to exceed three years on average.

In the context of mood disorders, BZD w/ patients were more frequently outpatients than inpatients (respectively $88.9 \%$ vs $77.5 \%$, and $11.7 \%$ vs $22.5 \%$ ), particularly among bipolar subjects (outpatients $88.9 \%$ vs $59.4 \%$; inpatients $11.1 \%$ vs $40.6 \%$ ). In fact, as symptomatic drugs (Verster \& Volkerts, 2004), BZDs provide a fast relief for insomnia and comorbid anxious symptoms, especially for outpatients, who tend to start taking these medications at their home. Indeed, patients who were firstly administered BZDs presented more often anxious symptoms at onset (22.3\% vs $10.5 \%$ ), while depressive, psychotic or other onset symptoms did not differ between groups. Nardi and colleagues previously confirmed the aforementioned association between anxious symptoms and use of BZDs in patients with mood spectrum disorders (Nardi et al., 2008). Nonetheless, the presence of anxious symptoms should rather be considered a reason to start a guidelinerecommended treatment, like a second-generation antidepressant, rather than a BZD(Baldwin et al., 2014). (Gaspersz, Nawijn, Lamers, \& Penninx, 2018)

BZD w/ subjects were more frequently affected by AD (14.3\% vs 6.3\%) and less frequently by BD ( $16.1 \%$ vs 33.9) compared to BZD w/o ones, while no difference emerged in relation to MDD rates. A previous study with a large sample showed that more than $50 \%$ of the AD patients were disabled by their symptoms, with frequent BZDs administration (Arbus et al., 2014). Actually, a limited literature on BZDs use in patients with $\mathrm{AD}$ is available and, to date, no specific psychotropic has been approved for this indication (Casey, 2014). Of note, the DUI was found to be longer in BZD w/ vs BZD w/o patients affected by $\operatorname{AD}(38.3 \pm 63.2$ vs $3.0 \pm 5.4$ months $)$. 
Another relevant finding of the present study indicates that psychologist or other therapists (in particular GPs) more frequently represented the first therapist for BZD w/ patients (respectively $22.3 \%$ vs $7.9 \%$; $51.3 \%$ vs $38.2 \%)$, rather than psychiatrists $(25.9 \%$ vs $53.9 \%)$. The same result was found for MDD (psychologist $21.8 \%$ vs $11.3 \%$, psychiatrist $23.1 \%$ vs $43.5 \%$ ) and for anxiety spectrum disorders (psychiatrist $17.0 \%$ vs $48.0 \%$, other doctor $62.0 \%$ vs $40.0 \%$; Figure 1). Previous investigation reported converging results both in Italian (Dell'Osso et al., 2015) and European samples. In this perspective, Alonso and colleagues in the ESEMeD study showed that only $25.7 \%$ of individuals with a previous 12-month diagnosis of mental disorder used a formal health service (i.e., psychiatrist, psychologist, specialized nurse, general practitioner, or any other medical doctor). Among these, $33.4 \%$ consulted a GP, $19.6 \%$ a psychiatrist, $13.5 \%$ a psychologist/counsellor and $28 \%$ both a GP and a mental health professional. Formal mental health service use was more frequent among individuals with mood compared to anxiety disorders. Among European countries, Italy showed a lower, statistically significant likelihood of consultation with formal health services (Alonso et al., 2004). Taken as a whole, these results seem to support the view that BZDs may be more frequently prescribed by non-psychiatrist therapists in patients with mood spectrum disorders. In addition, this finding seems to be linked to the observed delayed latency to first diagnosis, previously discussed, which converge in defining an incorrect and dangerous approach to mental health services for many patients with affective disorders, based on the following assumptions: minor presence of psychiatrist as first therapist, more frequent first BZD prescription, long latency to first diagnosis and, ultimately, longer DUI (i.e., longer latency to a guideline-recommended treatment (e.g., antidepressants, mood stabilizers).

Focusing on pharmacological prescriptions, indeed, BZDs are frequently prescribed in mood disorders as initial treatments (Baldwin et al., 2012; Dell'Osso \& Lader, 2013), even though treatment guidelines recommend the use of an antidepressant treatment (Baldwin et al., 2014; Starcevic, 2014). Actually, Bushnell and colleagues showed, in a large sample of 765 depressed patients, no significant clinical differences in continuation of antidepressant treatment between simultaneous administration of BZDs plus antidepressant and antidepressant alone (Bushnell et al., 2017; Rizvi, Sproule, Gallaugher, McIntyre, \& Kennedy, 2015a). (Benasi et al., 2018)Furthermore, as BZD dependence may develop shortly after their initial administration (Lader, 1991; Youssef \& Rich, 2008), BZDs in mood disorders should be more cautiously prescribed.

Interestingly, in relation to the specific diagnosis of MDD, BZD w/ patients more frequently sought for treatment following a personal decision than BZD w/o ones $(53.5 \%$ vs $38.5 \%$, p<0.05). Demyttenaere and colleagues, in the ESEMeD project study, reported that help seeking behaviour (defined as consultation with any of formal healthcare providers, such as psychiatrist, psychologist, 
general practitioner or any other medical doctor) significantly increased the use of BZDs compared to non-help seeking subjects (Demyttenaere et al., 2008). Our findings and Demyttenaere's report might therefore suggest that the use of BZDs as first therapy is common among patients suffering from mood and anxiety disorders, and particularly among those who then decide to autonomously seek for help.

Considering anxiety spectrum disorders, BZD w/ subjects were more frequently females $(60.0 \%$ vs $35.0 \%)$ and more often presented phobias (47.0\% vs $23.0 \%)$ and onset-related stressful life events (79.0\% vs 58\%) than BZD w/o ones. In this respect, female patients were found to be more frequently BZD users in several reports. Among those, Peters and colleagues analysed multiple demographic and clinical factors associated with BZD prescription at patients' discharge from psychiatric unit, reporting that women had a greater likelihood of receiving BZDs (Peters, Knauf, Derbidge, Kimmel, \& Vannoy, 2015). Also Demyttenaere and colleagues, in the ESEMeD study, reported that, beyond specific clinical factors, female gender was more frequently associated with BZD use in the last year (Demyttenaere et al., 2008). Moreover, other studies showed that BZD use tends to be higher in female patients not only when focusing on GPs prescriptions in the general population (Moßhammer et al., 2017), but also in patients suffering from depression, anxiety and/or insomnia (Rizvi, Sproule, Gallaugher, McIntyre, \& Kennedy, 2015b; Sjöstedt, Ohlsson, Li, \& Sundquist, 2017).

Finally, in anxiety spectrum disorders, BZD w/ subjects were more frequently affected by GAD (58.0\% vs $39.0 \%)$ and less frequently by OCD (10.0\% vs $30.0 \%)$ than BZD w/o ones. This result can reflect current evidence regarding BZDs use in such conditions, wider for patients with GAD, even with a low overall guideline recommendation level. In fact, in the available literature, the role of BZDs in GAD is debated:(Dell'Osso \& Lader, 2013)(Offidani, Guidi, Tomba, \& Fava, 2013)(Rickels \& Moeller, 2018), these compounds having a rapid relief for anxiety symptoms despite their long-term side effects and abuse risk (B Dell'osso \& Lader, 2013). (Balon et al., 2018) al(Fava \& Belaise, 2018; Jha, Rush, \& Trivedi, 2018) For instance, WFSBP guidelines ranked BZDs use in GAD with the highest category of evidence (A) and a moderate risk-benefit ratio, while their use is not mentioned in OCD (Bandelow et al., 2008), being poorly supported by available evidence.

Even though our sample resulted to be quite representative, the following methodological limitations should be considered to interpret the aforementioned findings. Since the POLT-Q retrospectively collected socio-demographic and clinical variables, the presence of recall bias cannot be excluded, particularly for patients with most remote onset, like elderly people. 
Nonetheless, as already mentioned, all clinical data from the POLT-Q were cross-checked with family members/caregivers and previous medical charts, when available. Moreover, the recruitment of patients coming from different catchment areas may have reflected local differences in terms of efficiency of psychiatric services as well as different socio-cultural attitudes, which, in turn, may have influenced reported results. Indeed, the prevalence of BZDs prescription varied considerably across different populations and several clinical factors could have influenced the results, including the epoch of recruitment, with patients with more recent onset having likely access to more suitable pathways of mental health care compared with individuals with a more distant onset, as we previously pointed out (Dell'Osso et al., 2016)

\section{CONCLUSION}

We contend that the identification of socio-demographic and clinical aspects related to potentially inappropriate initial prescription of BZDs in affective disorders could be highly useful to prevent subsequent misuse and related side effects and risks (Baldwin et al., 2013). Consequently, a more careful psychiatrist-oriented approach to first diagnosis and pharmacological prescription might reduce the incorrect prescription of first BZDs and a delayed latency to first diagnosis and first guideline-recommended treatment in patients with affective disorders, likely limiting BZD related long-term side effects, abuse and withdrawal concerns (Donoghue \& Lader, 2010), with the ultimate aim to early begin an adequate treatment rather than a symptomatic therapy. Further replication studies are needed to corroborate our results. 
Table 1. Socio-demographic and clinical variables of the total sample and related subgroups (BZDs w/ and BZD w/o).

\begin{tabular}{|c|c|c|c|}
\hline & Total Sample & BZDw/o $\quad(n=296)$ & $\mathrm{BZDw} /(\mathrm{n}=164)$ \\
\hline $\begin{array}{l}\text { Gender: male } \\
\text { female }\end{array}$ & $\begin{array}{l}236(51.3 \%) \\
224(48.7 \%)\end{array}$ & $\begin{array}{l}161(54.4 \%) \\
135(45.6 \%)\end{array}$ & $\begin{array}{l}75(45.7 \%) \\
89(54.3 \%)\end{array}$ \\
\hline Age (years) & $48.57 \pm 14.35$ & $48.51 \pm 13.83$ & $48.68 \pm 15.23$ \\
\hline Age at onset (years) & $32.26 \pm 14.27$ & $32.10 \pm 14.27$ & $32.54 \pm 14.30$ \\
\hline Age of first diagnosis (years) & $36.81 \pm 13.99$ & $36.58 \pm 13.87$ & $37.23 \pm 14.24$ \\
\hline Age at first pharmacological treatment (years) & $37.45 \pm 14.11$ & $36.66 \pm 13.42$ & $38.87 \pm 15.23$ \\
\hline DUI (years) & $5.19 \pm 8.60$ & $4.56 \pm 8.25$ & $6.33 \pm 9.11$ \\
\hline DUI (months) & $62.28 \pm 103.16$ & $54.70 \pm 98.96$ & $75.96 \pm 109.33$ \\
\hline $\begin{array}{l}\text { Time between BZD treatment-OTHER treatment } \\
\text { (months) }\end{array}$ & $48.01 \pm 79.15$ & - & $48.01 \pm 79.15$ \\
\hline Age at first BZD treatment & $35.43 \pm 14.25$ & - & $35.43 \pm 14.25$ \\
\hline
\end{tabular}


Table 2. Socio-demographic and clinical features of BZDw/ vs and w/o in patients with mood and anxiety spectrum disorders and related diagnoses.

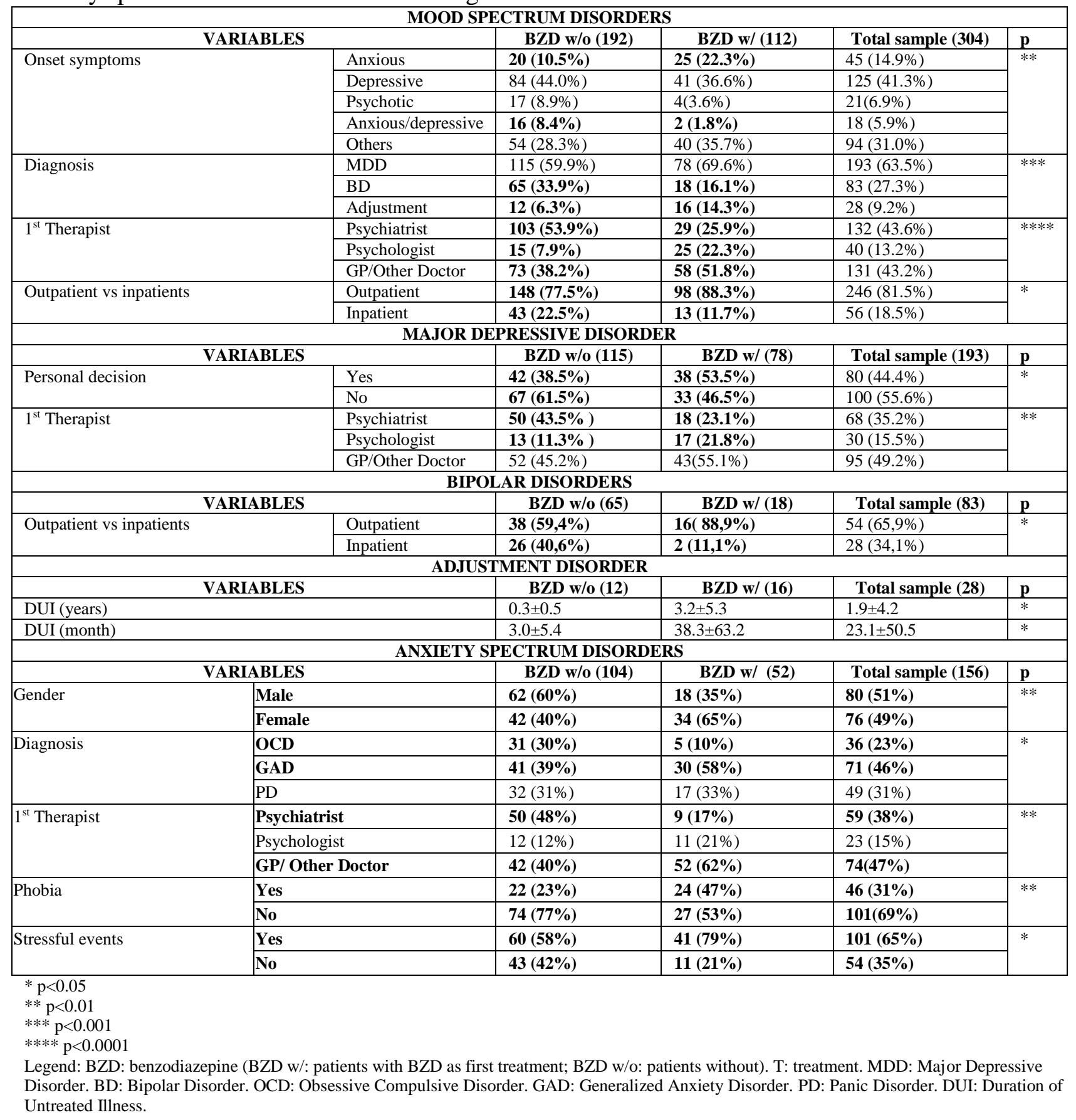


Figure 1 First therapist in Mood and Anxiety disorders: a comparison between BZD w/o and BZD w/ patients

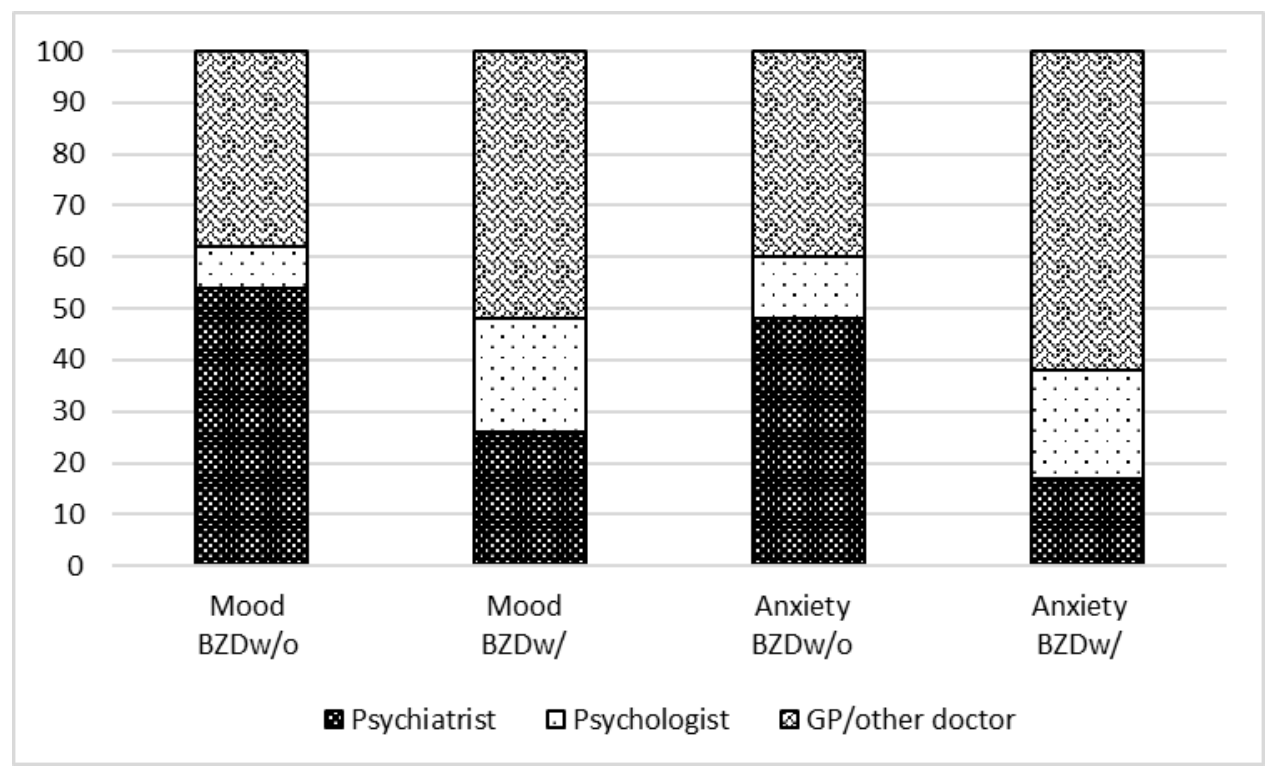




\section{References}

Alonso, J., Angermeyer, M. C., Bernert, S., Bruffaerts, R., Brugha, T. S., Bryson, H., ... ESEMeD/MHEDEA 2000 Investigators, European Study of the Epidemiology of Mental Disorders (ESEMeD) Project. (2004). Use of mental health services in Europe: results from the European Study of the Epidemiology of Mental Disorders (ESEMeD) project. Acta Psychiatrica Scandinavica. Supplementum, 109(420), 47-54. http://doi.org/10.1111/j.1600-0047.2004.00330.x

American Psychiatric Association. (2000). Diagnostic and Statistical Manual of Mental Disorders, 4th Edition, Text Revision (DSM-IV-TR) (Fourth Edi).

Anthierens, S., Habraken, H., Petrovic, M., Deveugele, M., De Maeseneer, J., \& Christiaens, T. (2007). First benzodiazepine prescriptions: qualitative study of patients' perspectives. Canadian Family Physician Medecin de Famille Canadien, 53(7), 1200-1. Retrieved from http://www.ncbi.nlm.nih.gov/pubmed/17872818

Arbus, C., Hergueta, T., Duburcq, A., Saleh, A., Le Guern, M.-E., Robert, P., \& Camus, V. (2014). Adjustment disorder with anxiety in old age: Comparing prevalence and clinical management in primary care and mental health care. European Psychiatry, 29(4), 233-238. http://doi.org/10.1016/j.eurpsy.2013.04.002

Baldwin, D. S., Aitchison, K., Bateson, A., Curran, H. V., Davies, S., Leonard, B., ... Wilson, S. (2013). Benzodiazepines: risks and benefits. A reconsideration. Journal of Psychopharmacology (Oxford, England), 27(11), 967-71. http://doi.org/10.1177/0269881113503509

Baldwin, D. S., Allgulander, C., Bandelow, B., Ferre, F., \& Pallanti, S. (2012). An international survey of reported prescribing practice in the treatment of patients with generalised anxiety disorder. The World Journal of Biological Psychiatry: The Official Journal of the World Federation of Societies of Biological Psychiatry, 13(7), 510-6. http://doi.org/10.3109/15622975.2011.624548

Baldwin, D. S., Anderson, I. M., Nutt, D. J., Allgulander, C., Bandelow, B., den Boer, J. A., ... Wittchen, H.-U. (2014). Evidence-based pharmacological treatment of anxiety disorders, post-traumatic stress disorder and obsessivecompulsive disorder: a revision of the 2005 guidelines from the British Association for Psychopharmacology. Journal of Psychopharmacology (Oxford, England), 28(5), 403-39. http://doi.org/10.1177/0269881114525674

Balon, R., Chouinard, G., Cosci, F., Dubovsky, S. L., Fava, G. A., Freire, R. C., ... Weintraub, S. J. (2018). International Task Force on Benzodiazepines. Psychotherapy and Psychosomatics, 87(4), $193-194$. http://doi.org/10.1159/000489538

Bandelow, B., Zohar, J., Hollander, E., Kasper, S., Möller, H.-J., WFSBP TASK FORCE ON TREATMENT GUIDE, ... Vega, J. (2008). World Federation of Societies of Biological Psychiatry (WFSBP) Guidelines for the Pharmacological Treatment of Anxiety, Obsessive-Compulsive and Post-Traumatic Stress Disorders - First Revision. The World Journal of Biological Psychiatry, 9(4), $248-312$. http://doi.org/10.1080/15622970802465807

Bauer, M., Pfennig, A., Severus, E., Whybrow, P. C., Angst, J., Möller, H.-J., \& World Federation of Societies of Biological Psychiatry. Task Force on Unipolar Depressive Disorders. (2013). World Federation of Societies of Biological Psychiatry (WFSBP) guidelines for biological treatment of unipolar depressive disorders, part 1: update 2013 on the acute and continuation treatment of unipolar depressive disorders. The World Journal of Biological Psychiatry: The Official Journal of the World Federation of Societies of Biological Psychiatry, 14(5), 334-85. http://doi.org/10.3109/15622975.2013.804195

Benasi, G., Guidi, J., Offidani, E., Balon, R., Rickels, K., \& Fava, G. A. (2018). Benzodiazepines as a Monotherapy in Depressive Disorders: A Systematic Review. Psychotherapy and Psychosomatics, 87(2), 65-74. http://doi.org/10.1159/000486696

Bushnell, G. A., Stürmer, T., Gaynes, B. N., Pate, V., \& Miller, M. (2017). Simultaneous Antidepressant and Benzodiazepine New Use and Subsequent Long-term Benzodiazepine Use in Adults With Depression, United States, 2001-2014. JAMA Psychiatry, 74(7), 747-755. http://doi.org/10.1001/jamapsychiatry.2017.1273

Busto, U. E., \& Sellers, E. M. (1991). Anxiolytics and sedative/hypnotics dependence. British Journal of Addiction, 86(12), 1647-52. Retrieved from http://www.ncbi.nlm.nih.gov/pubmed/1686199 
Casey, P. (2014). Adjustment disorder: new developments. Current Psychiatry Reports, $16(6), 451$. http://doi.org/10.1007/s11920-014-0451-2

Charara, R., Forouzanfar, M., Naghavi, M., Moradi-Lakeh, M., Afshin, A., Vos, T., ... Mokdad, A. H. (2017). The Burden of Mental Disorders in the Eastern Mediterranean Region, 1990-2013. PloS One, 12(1), e0169575. http://doi.org/10.1371/journal.pone.0169575

Del Vecchio, V., Luciano, M., Sampogna, G., De Rosa, C., Giacco, D., Tarricone, I., ... Fiorillo, A. (2015). The role of relatives in pathways to care of patients with a first episode of psychosis. The International Journal of Social Psychiatry, 61(7), 631-7. http://doi.org/10.1177/0020764014568129

Dell'osso, B., \& Altamura, A. C. (2010). Duration of untreated psychosis and duration of untreated illness: new vistas. CNS Spectrums, 15(4), 238-46. Retrieved from http://www.ncbi.nlm.nih.gov/pubmed/20414173

Dell'Osso, B., Camuri, G., Benatti, B., Buoli, M., \& Altamura, A. C. (2013). Differences in latency to first pharmacological treatment (duration of untreated illness) in anxiety disorders: a study on patients with panic disorder, generalized anxiety disorder and obsessive-compulsive disorder. Early Intervention in Psychiatry, 7(4), 374-80. http://doi.org/10.1111/eip.12016

Dell'Osso, B., Cremaschi, L., Palazzo, C., Suardi, N., Spagnolin, G., Camuri, G., ... Altamura, A. C. (2015). Factors characterizing access and latency to first pharmacological treatment in Italian patients with schizophrenia, mood, and anxiety spectrum disorders. International Clinical Psychopharmacology, 30(1), 29-35. http://doi.org/10.1097/YIC.0000000000000049

Dell'Osso, B., \& Lader, M. (2013). Do benzodiazepines still deserve a major role in the treatment of psychiatric disorders? A critical reappraisal. European Psychiatry, 28(1), 7-20. http://doi.org/10.1016/j.eurpsy.2011.11.003

Dell’Osso, B., Oldani, L., Camuri, G., Benatti, B., Grancini, B., Arici, C., ... Altamura, A. C. (2016). Reduced duration of untreated illness over time in patients with schizophrenia spectrum, mood and anxiety disorders. Psychiatry and Clinical Neurosciences, 70(5), 202-10. http://doi.org/10.1111/pcn.12380

Dell'Osso B, Palazzo C, A. C. et al. (2011). Development of a short questionnaire for the assessment of the onset and latency to treatments in psychiatric disorders. Poster Presentation 164 Annual Meeting of the American Psychiatry Association, Honolulu, Hawaii.

Demyttenaere, K., Bonnewyn, A., Bruffaerts, R., De Girolamo, G., Gasquet, I., Kovess, V., ... Alonso, J. (2008). Clinical factors influencing the prescription of antidepressants and benzodiazepines: results from the European study of the epidemiology of mental disorders (ESEMeD). Journal of Affective Disorders, 110(1-2), 84-93. http://doi.org/10.1016/j.jad.2008.01.011

Donoghue, J., \& Lader, M. (2010). Usage of benzodiazepines: A review. International Journal of Psychiatry in Clinical Practice, 14(2), 78-87. http://doi.org/10.3109/13651500903447810

Falloon, I. R. (2000). General practice recruitment for people at risk of schizophrenia: the Buckingham experience. The Australian and New Zealand Journal of Psychiatry, 34 Suppl(2_suppl), S131-6-4. http://doi.org/10.1080/000486700233

Fava, G. A., \& Belaise, C. (2018). Discontinuing Antidepressant Drugs: Lesson from a Failed Trial and Extensive Clinical Experience. Psychotherapy and Psychosomatics, 87(5), 257-267. http://doi.org/10.1159/000492693

First MB, Michael B, S. R. et al. (2002). Structured Clinical Interview for DSM-IV-TR Axis I Disorders, Research Version, Patient Edition (SCID-I). Biometrics Research, New York State Psychiatry.

Fride Tvete, I., Bjørner, T., \& Skomedal, T. (2015). Risk factors for excessive benzodiazepine use in a working age population: a nationwide 5-year survey in Norway. Scandinavian Journal of Primary Health Care, 33(4), 252-9. http://doi.org/10.3109/02813432.2015.1117282

Gaspersz, R., Nawijn, L., Lamers, F., \& Penninx, B. W. J. H. (2018). Patients with anxious depression: overview of prevalence, pathophysiology and impact on course and treatment outcome. Current Opinion in Psychiatry, 31(1), 17-25. http://doi.org/10.1097/YCO.0000000000000376

Grancini, B., De Carlo, V., Palazzo, M., Vismara, M., Arici, C., Cremaschi, L., ... Dell'Osso, B. (2018). Does initial use of benzodiazepines delay an adequate pharmacological treatment? International Clinical Psychopharmacology, 33(3), 1. http://doi.org/10.1097/YIC.0000000000000210 
Grunze, H., Vieta, E., Goodwin, G. M., Bowden, C., Licht, R. W., Möller, H.-J., ... WFSBP Task Force on Treatment Guidelines for Bipolar Disorders. (2013). The World Federation of Societies of Biological Psychiatry (WFSBP) guidelines for the biological treatment of bipolar disorders: update 2012 on the long-term treatment of bipolar disorder. The World Journal of Biological Psychiatry: The Official Journal of the World Federation of Societies of Biological Psychiatry, 14(3), 154-219. http://doi.org/10.3109/15622975.2013.770551

Janhsen, K., Roser, P., \& Hoffmann, K. (2015). The problems of long-term treatment with benzodiazepines and related substances. Deutsches Arzteblatt International, 112(1-2), 1-7. http://doi.org/10.3238/arztebl.2015.0001

Jha, M. K., Rush, A. J., \& Trivedi, M. H. (2018). When Discontinuing SSRI Antidepressants Is a Challenge: Management Tips. American Journal of Psychiatry, 175(12), 1176-1184. http://doi.org/10.1176/appi.ajp.2018.18060692

Lader, M. (1991). History of benzodiazepine dependence. Journal of Substance Abuse Treatment, 8(1-2), 53-9. Retrieved from http://www.ncbi.nlm.nih.gov/pubmed/1675692

Moßhammer, D., Haumann, H., Muche, R., Scheub, D., Joos, S., \& Laux, G. (2017). [Prescription of Benzodiazepines and Z-Drugs by German General Practitioners: A Cross-Sectional Study]. Gesundheitswesen (Bundesverband Der Arzte Des Offentlichen Gesundheitsdienstes (Germany)). http://doi.org/10.1055/s-0043-104694

Nardi, A. E., Freire, R. C., Valença, A. M., Amrein, R., de Cerqueira, A. C. R., Lopes, F. L., ... Versiani, M. (2010). Tapering clonazepam in patients with panic disorder after at least 3 years of treatment. Journal of Clinical Psychopharmacology, 30(3), 290-3. http://doi.org/10.1097/JCP.0b013e3181dcb2f3

Nardi, A. E., Nascimento, I., Freire, R. C., Veras, A. B., De-Melo-Neto, V. L., Valença, A. M., ... Versiani, M. (2008). Demographic and clinical features of panic disorder comorbid with bipolar I disorder: a 3-year retrospective study. Journal of Affective Disorders, 106(1-2), 185-9. http://doi.org/10.1016/j.jad.2007.05.026

Offidani, E., Guidi, J., Tomba, E., \& Fava, G. A. (2013). Efficacy and tolerability of benzodiazepines versus antidepressants in anxiety disorders: a systematic review and meta-analysis. Psychotherapy and Psychosomatics, 82(6), 355-62. http://doi.org/10.1159/000353198

Paquin, A. M., Zimmerman, K., \& Rudolph, J. L. (2014). Risk versus risk: a review of benzodiazepine reduction in older adults. Expert Opinion on Drug Safety, 13(7), 919-934. http://doi.org/10.1517/14740338.2014.925444

Peters, S. M., Knauf, K. Q., Derbidge, C. M., Kimmel, R., \& Vannoy, S. (2015). Demographic and clinical factors associated with benzodiazepine prescription at discharge from psychiatric inpatient treatment. General Hospital Psychiatry, 37(6), 595-600. http://doi.org/10.1016/j.genhosppsych.2015.06.004

Rickels, K., \& Moeller, H. J. (2018). Benzodiazepines in anxiety disorders: Reassessment of usefulness and safety. The World Journal of Biological Psychiatry: The Official Journal of the World Federation of Societies of Biological Psychiatry, 1-5. http://doi.org/10.1080/15622975.2018.1500031

Rizvi, S. J., Sproule, B. A., Gallaugher, L., McIntyre, R. S., \& Kennedy, S. H. (2015a). Correlates of benzodiazepine use in major depressive disorder: The effect of anhedonia. Journal of Affective Disorders, 187, 101-5. http://doi.org/10.1016/j.jad.2015.07.040

Rizvi, S. J., Sproule, B. A., Gallaugher, L., McIntyre, R. S., \& Kennedy, S. H. (2015b). Correlates of benzodiazepine use in major depressive disorder: The effect of anhedonia. Journal of Affective Disorders, 187, 101-5. http://doi.org/10.1016/j.jad.2015.07.040

Sjöstedt, C., Ohlsson, H., Li, X., \& Sundquist, K. (2017). Socio-demographic factors and long-term use of benzodiazepines in patients with depression, anxiety or insomnia. Psychiatry Research, 249, 221-225. http://doi.org/10.1016/j.psychres.2017.01.046

Skeate, A., Jackson, C., Birchwood, M., \& Jones, C. (2002). Duration of untreated psychosis and pathways to care in first-episode psychosis. Investigation of help-seeking behaviour in primary care. The British Journal of Psychiatry. Supplement, 43, s73-7.

Starcevic, V. (2014). The reappraisal of benzodiazepines in the treatment of anxiety and related disorders. Expert Review of Neurotherapeutics, 14(11), 1275-86. http://doi.org/10.1586/14737175.2014.963057

Straand, J., \& Rokstad, K. (1997). General practitioners' prescribing patterns of benzodiazepine hypnotics: are elderly patients at particular risk for overprescribing? A report from the Møre \&amp; Romsdal Prescription Study. 
Scandinavian Journal of Primary Health Care, 15(1), 16-21.

Tait, L., Lester, H., Birchwood, M., Freemantle, N., \& Wilson, S. (2005). Design of the BiRmingham Early Detection In untREated psyChosis Trial (REDIRECT): cluster randomised controlled trial of general practitioner education in detection of first episode psychosis [ISRCTN87898421]. BMC Health Services Research, 5(1), 19. http://doi.org/10.1186/1472-6963-5-19

Verster, J. C., \& Volkerts, E. R. (2004). Clinical pharmacology, clinical efficacy, and behavioral toxicity of alprazolam: a review of the literature. CNS Drug Reviews, 10(1), 45-76. Retrieved from http://www.ncbi.nlm.nih.gov/pubmed/14978513

Youssef, N. A., \& Rich, C. L. (2008). Does acute treatment with sedatives/hypnotics for anxiety in depressed patients affect suicide risk? A literature review. Annals of Clinical Psychiatry : Official Journal of the American Academy of Clinical Psychiatrists, 20(3), 157-69. http://doi.org/10.1080/10401230802177698 